\title{
Efficacy and Safety of Letrozole in the Management of Constitutional Delay in Growth and Puberty: A Systematic Review and Meta-analysis
}

\author{
(1) Deep Dutta ${ }^{1}$, (1) Rajiv Singla2 , (1) Vineet Surana ${ }^{3}$, (1) Meha Sharma ${ }^{4}$ \\ ${ }^{1}$ CEDAR Superspeciality Clinics, Department of Endocrinology, New Delhi, India \\ ${ }^{2}$ Kalpavriksh Superspeciality Healthcare, Department of Endocrinology, New Delhi, India \\ 3 Manipal Hospitals, Department of Endocrinology, New Delhi, India \\ ${ }^{4}$ CEDAR Superspeciality Clinics, Department of Rheumatology, New Delhi, India
}

\begin{abstract}
No meta-analysis is available which has analysed the role of letrozole in constitutional delay in growth and puberty (CDGP). Electronic databases were searched for randomized controlled trials (RCTs) involving children with CDGP receiving letrozole. Primary outcomes were changes in predicted adult height (PAH) and pubertal progression. Secondary outcomes were alterations in bone age (BA), hormonal markers of puberty, bone mineral density and side-effects. One hundred-thirty articles were reviewed, from which seven RCTs which fulfilled all criteria were analysed. Letrozole was superior to placebo [mean difference (MD) $4.63 \mathrm{~cm}$ (95\% confidence interval (CI): 3.90 5.36); $\mathrm{p}<0.01 ; \mathrm{I} 2=0 \%$ ] but not testosterone [MD: $2.21 \mathrm{~cm}(95 \% \mathrm{CI}:-1.71-6.16) ; \mathrm{p}=0.27 ; \mathrm{I}^{2}=98 \%$ ] with regards to improvement in PAH after 12-months use. Letrozole was superior to both placebo [MD: $4.80 \mathrm{~mL}$ (95\% CI: 0.57-9.03); p=0.03] and testosterone [MD: $3.36 \mathrm{~mL}$ (95\% CI: 0.58-6.75); $\mathrm{p}=0.02 ; \mathrm{I}^{2}=0 \%$ ] with regards to improvement in testicular volume after 12-months use. Letrozole tended to be superior to testosterone [MD: -0.84 years $(95 \% \mathrm{CI}: 2.83-8.18) ; \mathrm{p}=0.06 ; \mathrm{I}^{2}=0 \%$ ] with regards to slowing in BA progression after 12 -months use. Serum luteinizing hormone, follicle stimulating hormone, testosterone and inhibin-B were significantly higher after 6-months letrozole use compared to active as well as passive controls. No increased occurrence of adverse events, including spinal deformities, were noted with letrozole. Letrozole is safe and effective for improving height and pubertal outcomes in CDGP, and is better than testosterone with regards to improvement in testicular volume and may be better at delaying bone-age progression.
\end{abstract}

Keywords: Letrozole, meta-analysis, safety, constitutional delay in growth and puberty, short stature

\section{Introduction}

Constitutional delay in growth and puberty (CDGP) is perhaps the most common cause of short stature in both the sexes; and for not yet determined reasons, is much more common in boys than girls (1). The diagnosis of CDGP is often a diagnosis of exclusion (2). Children with CDGP have delayed pubertal growth spurt and usually have catchup growth with the late onset of puberty, by 18 years age (2). Although reassurance and watchful waiting is recommended in CDGP, many children with CDGP in their teenage years have associated significant psychosocial stress, negative interaction with peers, anxiety or depression, warranting medical intervention (3). Suggested interventions include medications which will promote sexual maturation (4). Traditionally, low dose testosterone injections/oxandrolone and ethinyl estradiol/estradiol patches have been tried to accelerate puberty in boys and girls, respectively, for many decades now (4). Recently a few trials have been published which have suggested that letrozole may have a role in activation of the hypothalamic-pituitary-gonad (HPG) axis and faster testicular growth, resulting in accelerated height growth and pubertal progression in $\operatorname{CDGP}(5,6)$.

Theoretically, aromatase inhibitors are uniquely suited to manage different aspects of CDGP. Letrozole would delay bone maturation by inhibiting conversion of testosterone to estradiol and thereby lowering blood estradiol concentrations 
(7). Letrozole also has the potential to induce maturation of the HPG axis by decreasing the negative feedback loop from estradiol to the hypothalamus. Some safety concerns include reduced bone density, which have primarily been documented in adult cancer survivors (8).

However, to date, no meta-analysis is available which has holistically analysed and summarized the clinical efficacy and safety of letrozole in CDGP. Hence the aim of this metaanalysis was to evaluate the efficacy and safety of letrozole in the management of CDGP.

\section{Methodology}

The meta-analysis was carried out according to the recommendations of the Cochrane Handbook for Systematic Reviews of Interventions (9). The predefined protocol has been registered in PROSPERO, having the registration number CRD42021250345. All randomized controlled trials (RCTs) published up to March 2021 were considered for this meta-analysis. This meta-analysis has been reported in accordance with the Preferred Reporting Items for Systematic Reviews and Meta-Analyses (PRISMA) criteria, the filled checklist of which can be found at the end of the manuscript (9). Since ethical approval already exists for the individual studies included in the meta-analysis, no separate approval was required for this study.

The PICOS criteria was used to screen and select the studies for this meta-analysis with patients (P) being children diagnosed with CDGP; intervention (I) being the use of letrozole for managing CDGP; control (C) being patients either on placebo or any other approved medication for managing CDGP, which included testosterone, oxandrolone or estradiol; outcomes $(\mathrm{O})$ being evaluated were impact on predicted adult height (PAH), height standard deviation score (Ht-SDS), bone age (BA), clinical and hormonal measures of puberty and any adverse effects noted; and (S) being studies included which were RCTs. Only children with CDGP were considered for this meta-analysis. Children with other forms or causes of short stature, such as familial short stature, growth hormone deficiency, panhypopituitarism, syndromic short stature, and idiopathic short stature were excluded. Only those studies were included in this metaanalysis which had at least two treatment groups of children with CDGP, with one of the groups receiving letrozole and the other group receiving either placebo or any other medication in place of letrozole.

The primary outcomes were to evaluate the changes in $\mathrm{PAH}$ and pubertal progression, as determined by testicular volume. The secondary outcomes were to evaluate the alterations in Ht-SDS, final height, BA, hormonal markers of puberty [including testosterone, luteinizing hormone (LH), follicle stimulating hormone (FSH), estradiol, inhibin-B, and anti-Müllerian hormone], bone mineral density (BMD), body composition changes (lean mass, fat mass), and any side effects reported. Analysis of the growth and puberty outcomes was based on whether the control group received an active comparator (like testosterone, oxandrolone or any other approved medication for use in CDGP) - labelled here as the active control group (ACG) or a placebo/nothing labelled as passive/placebo control group (PCG).

\section{Search Method for Identification of Studies}

A detailed search was done of electronic databases of Medline (Via PubMed), Embase (via Ovid SP), Cochrane central register of controlled trials (CENTRAL) (for trials only), ctri.nic.in, clinicaltrials.gov, global health and Google scholar using a Boolean search strategy: (letrozole) AND [(delayed puberty) OR (short stature)].

\section{Data Extraction and Study Selection}

Data extraction was carried out independently by two authors using standard data extraction forms. In cases where more than one publication of a single study group were found, results were grouped and relevant data from each report were used in the analyses. Data on the primary and secondary outcomes, as stated above, was extracted. Patient characteristics (including demographic information and comorbidities) from the different studies included and excluded from the analysis were noted in a tabular form (Table 1,2). All disagreements were resolved by the third and fourth authors.

\section{Assessment of Risk of Bias in Included Studies}

Three authors independently assessed the risk of bias using the risk of bias assessment tool in Review Manager (Revman) Version 5.3 (The Cochrane Collaboration, Oxford, UK, 2014) software. The following points were taken into consideration when assessing if there was adequate sequence generation to rule out selection bias. We examined if the patient group allocation reconcealed adequately to rule out selection bias. We also looked for whether researcher knowledge of the allocated interventions was adequately prevented during the study or not. Participants and personnel blinding was specifically looked for to rule out performance bias. We also looked for the blinding of the outcome assessors to rule out detection bias. We looked for whether incomplete outcome data issue was adequately addressed or not to rule out attrition bias. We also looked at if the reports of the study 
were free of suggestion of selective outcome reporting to rule out reporting bias. Lastly we also looked for whether the study was apparently free of other problems that could put it at risk of bias. Any disagreements were resolved by the fourth author. The risk of bias has been elaborated in Supplementary Table 1.

\section{Measures of Treatment Effect}

For continuous variables, the outcomes were expressed as mean differences (MD). International system (SI) units were used for analysis, and all studies reporting results in conventional units were converted to SI units for analysis. For dichotomous outcomes (treatment success) results were expressed as risk ratios (RR) with $95 \%$ confidence intervals (CI). For adverse events, results were expressed as post treatment absolute risk differences. RevMan 5.3 was used to compare MD of the different primary and secondary outcomes between letrozole and the control groups of the included studies.

\section{Assessment of Heterogeneity}

Heterogeneity was initially assessed by studying the forest plot generated for the primary and secondary outcomes of this study. Subsequently, heterogeneity was analysed using a chi ${ }^{2}$ test on $\mathrm{N}-1$ degrees of freedom, with an alpha of 0.05 used for statistical significance and with the $\mathrm{I}^{2}$ test (10). The

Table 1. Characteristics of patients in the different randomized controlled trials evaluated in this meta-analysis on use of letrozole in constitutional delay in growth and puberty

\begin{tabular}{|c|c|c|c|}
\hline Study details & $\begin{array}{l}\text { Number of patients in letrozole } \& \\
\text { control groups }\end{array}$ & Patient characteristics and nature of controls & Duration of study \\
\hline $\begin{array}{l}\text { Hero et al (2006) } \\
\text { (13) }\end{array}$ & $\begin{array}{l}\mathrm{Lz}+\mathrm{T}(\mathrm{n}=9) \\
\mathrm{T}+\text { Placebo }(\mathrm{n}=8) \\
\text { Testosterone was used at a dose of } 1 \mathrm{mg} / \\
\text { kg i.m. every } 4 \text { weeks for } 6 \text { months }\end{array}$ & $\begin{array}{l}\text { Children with testis volume }<4 \mathrm{~mL} \text { after } 13.5 \text { years } \\
\text { of age. }\end{array}$ & $\begin{array}{l}\text { Period of intervention } \\
52 \text { weeks; follow up } \\
4 \text { years }\end{array}$ \\
\hline $\begin{array}{l}\text { Hero et al (2010) } \\
(14)\end{array}$ & $\begin{array}{l}\mathrm{Lz}+\mathrm{T}(\mathrm{n}=6) \\
\mathrm{T}+\text { Placebo }(\mathrm{n}=6) \\
\text { Testosterone was used at a dose of } 1 \mathrm{mg} / \\
\text { kg intramuscularly every } 4 \text { weeks for } 6 \\
\text { months }\end{array}$ & $\begin{array}{l}\text { Children with testis volume }<4 \mathrm{~mL} \text { after } 13.5 \text { years } \\
\text { of age. }\end{array}$ & 52 weeks \\
\hline $\begin{array}{l}\text { Kohva et al (2020) } \\
(15)\end{array}$ & $\mathrm{Lz}(\mathrm{n}=15), \mathrm{T}(\mathrm{n}=13)$ & $\begin{array}{l}\text { The inclusion criteria were testicular volume between } \\
2.5 \text { and } 4 \mathrm{~mL} \text { and serum } \mathrm{T}<5 \mathrm{nmol} / \mathrm{L} \text { or serum } \mathrm{T} \geq 1 \\
\mathrm{nmol} / \mathrm{L} \text {, if the mean testicular volume was }<2.5 \mathrm{~mL} \text {, } \\
\text { or Tanner genital stage } 2 \text { and serum } \mathrm{T}<3 \mathrm{nmol} / \mathrm{L} \text {. At } \\
\text { the start of the trial, the boys were above } 14 \text { years of } \\
\text { age. Controls were similar to patients }\end{array}$ & 52 weeks \\
\hline $\begin{array}{l}\text { Rohani et al (2019) } \\
\text { (16) }\end{array}$ & $\begin{array}{l}\mathrm{Lz}(\mathrm{n}=8) \\
\text { Placebo }(\mathrm{n}=8)\end{array}$ & $\begin{array}{l}\text { PAH }<1 \text { SD MPH and Tanner pubic hair stage delayed } \\
\text { by }>\text { SD or TV }<=3 \mathrm{~mL}\end{array}$ & Follow up $\sim 8$ years \\
\hline $\begin{array}{l}\text { Salehpour et al } \\
(2010 \text { a) (6) }\end{array}$ & $\begin{array}{l}\mathrm{Lz}(\mathrm{n}=31) \\
\text { Oxandrolone }(\mathrm{n}=30)\end{array}$ & $\begin{array}{l}\text { 12.6-14.6 years old boys with } \mathrm{PAH}<1 \mathrm{SD} \mathrm{MPH} \text { and } \\
\text { Tanner pubic hair stage delayed by }>\text { SD or } \mathrm{TV}<=3 \\
\mathrm{~mL}\end{array}$ & $\begin{array}{l}\text { Intervention } 104 \text { weeks; } \\
\text { follow up } 260 \text { weeks }\end{array}$ \\
\hline $\begin{array}{l}\text { Salehpour et al } \\
(2010 b)(6)\end{array}$ & $\begin{array}{l}\mathrm{Lz}(\mathrm{n}=31) \\
\text { Placebo }(\mathrm{n}=30)\end{array}$ & $\begin{array}{l}\text { 12.6-14.6 years old boys with } \mathrm{PAH}<1 \mathrm{SD} \mathrm{MPH} \text { and } \\
\text { Tanner pubic hair stage delayed by }>\text { SD or } \mathrm{TV}<=3 \\
\mathrm{~mL}\end{array}$ & $\begin{array}{l}\text { Intervention } 104 \text { weeks; } \\
\text { follow up } 260 \text { weeks }\end{array}$ \\
\hline $\begin{array}{l}\text { Varimo et al (2019) } \\
\text { (5) }\end{array}$ & $\begin{array}{l}\text { Lz }(n=15) \\
\text { T ( } n=15) \text { (testosterone (Sustanon 250; } \\
\text { Aspen Nordic, Ballerup, Denmark) was } \\
\text { injected intramuscularly every } 4 \text { weeks } \\
\text { for } 6 \text { months (six injections in total) }\end{array}$ & $\begin{array}{l}\text { The inclusion criteria were testicular volume between } \\
2.5 \text { and } 4 \mathrm{~mL} \text { and serum } \mathrm{T}<5 \mathrm{nmol} / \mathrm{L} \text { or serum } \mathrm{T} \geq 1 \\
\mathrm{nmol} / \mathrm{L} \text {, if the mean testicular volume was }<2.5 \mathrm{~mL} \text {, } \\
\text { or Tanner genital stage } 2 \text { and serum } \mathrm{T}<3 \mathrm{nmol} / \mathrm{L} \text {. At } \\
\text { the start of the trial, the boys were above } 14 \text { years of } \\
\text { age. } \\
\text { Controls were similar to patients }\end{array}$ & $\begin{array}{l}\text { Intervention } 26 \text { weeks; } \\
\text { follow up } 52 \text { weeks }\end{array}$ \\
\hline $\begin{array}{l}\text { Wickman et al } \\
\text { (2001) (17) }\end{array}$ & $\begin{array}{l}\mathrm{Lz}+\mathrm{T}(\mathrm{n}=10) \\
\mathrm{T}+\text { Placebo }(\mathrm{n}=12) \text { (testosterone } \\
\text { enanthate (Testoviron- Depot- } 250 \text {, } \\
\text { Schering, Berlin, Germany) six times at a } \\
\text { dose of } 1 \mathrm{mg} / \mathrm{kg} \text { intramuscularly every } 4 \\
\text { weeks, and placebo orally once daily for } \\
12 \text { months) } \\
\text { Placebo }(n=10)\end{array}$ & $\begin{array}{l}\text { Children with testis volume }<4 \mathrm{~mL} \text { after } 13.5 \text { years } \\
\text { of age. }\end{array}$ & 18 months \\
\hline
\end{tabular}


interpretation of $\mathrm{I}^{2}$ values was as follows: $0 \%$ to $40 \%$ : might not be important; $40 \%$ to $60 \%$ : may represent moderate heterogeneity; $60 \%$ to $90 \%$ : may represent substantial heterogeneity; $90 \%$ to $100 \%$ : considerable heterogeneity. The importance of the observed value of $\mathrm{I}^{2}$ depends on the magnitude and direction of treatment effects and the strength of the evidence for heterogeneity (e.g. p value from the chi $^{2}$ test, or a CI for $\left.\mathrm{I}^{2}\right)(10)$.

\section{Grading of the Results}

An overall grading of the evidence (certainty of the evidence) related to each of the primary and secondary outcomes of the meta-analysis was done using the GRADE (Grades of Recommendation, Assessment, Development and Evaluation) approach (11). The GRADE approach defines the quality of a body of evidence as the extent to which one can be confident that an estimate of effect or association is close to the true quantity of specific interest. The quality of a body of evidence involves consideration of within-trial risk of bias (methodological quality), directness of evidence, heterogeneity, precision of effect estimates and risk of publication bias (11). The GRADEpro Guideline Development Tool software (McMaster University and Evidence Prime Inc, 2015) was used to create the Summary of Findings (SoF) table in this meta-analysis (Table 3). The "certainty of evidence" has been graded into four categories, namely "high" (there is a lot of confidence that the true effect lies close to that of the estimated effect), "moderate" (there is moderate confidence in the estimated effect: The true effect is likely to be close to the estimated effect, but there is a possibility that it is substantially different), "low" (there is limited effect in the estimated effect: The true effect might be substantially different from the estimated effect) and, "very low" (there is very little confidence in the estimated effect: The true effect is likely to be substantially different from the estimated effect) (11).
Publication bias was assessed by plotting the Funnel Plot, which specifically targets small study bias, in which small studies tend to show larger estimates of effects and greater variability than larger studies (9). Presence of one or more of the smaller studies outside the inverted funnel plot was taken as evidence of presence of significant publication bias (Supplementary Figure 1) (12).

\section{Data Synthesis}

Data was pooled as a random effect model for the analysis of primary and secondary outcomes. The outcomes were expressed as $95 \% \mathrm{CI}$. Forrest plots were plotted with the left side of the graph favouring letrozole and the right side of the graph favouring control using RevMan 5.3 software. A $p<0.05$ was considered statistically significant.

\section{Results}

A total of 357 articles were found after the initial search (Figure 1). Following the screening of the titles, and abstracts, the search came down to 173 articles. Thirty eight duplicates were removed. One hundred and thirty articles were reviewed in details from which seven RCTs which fulfilled all inclusion and exclusion criteria were included in the meta-analysis (Figure 1) $(5,6,13,14,15,16,17)$. One study was removed due to lack of a valid control group (18). Three studies evaluating impact on growth of letrozole in children with precocious puberty were excluded $(19,20,21)$.

Of the seven studies included in this meta-analysis, analysis was done based on the nature of the control group. The control was testosterone in the studies by Kohva et al (2020) (15) and Varimo et al (2019) (5) and hence the results from these studies have been analysed in the ACG. The controls were placebo in the studies by Hero et al (2006) (13), Hero et al (2010) (14), and Wickman et al (2001) (17), and hence

\begin{tabular}{|c|c|c|c|c|}
\hline Study details & $\begin{array}{l}\text { Number of patients in } \\
\text { study \& control groups }\end{array}$ & $\begin{array}{l}\text { Patient characteristics and nature of } \\
\text { controls }\end{array}$ & Duration of study & Reasons for exclusion \\
\hline $\begin{array}{l}\text { Neely et al } 2014 \\
\text { (20) }\end{array}$ & $\begin{array}{l}\text { Lz } 17 \\
\text { Anastrazole } 22\end{array}$ & $\begin{array}{l}\text { Short stature with reduced PAH in } \\
\text { prepubertal boys. } \\
\text { ISS and CDGP not differentiated }\end{array}$ & 24 months & $\begin{array}{l}\text { Lack of a matched control group } \\
\text { Not a randomized controlled trial }\end{array}$ \\
\hline Xu et al 2021 (21) & $\mathrm{GH}+\mathrm{Lz}$ single arm & $\begin{array}{l}\text { Short stature with reduced PAH in } \\
\text { prepubertal boys. } \\
\text { ISS and CDGP not differentiated }\end{array}$ & 12 months & $\begin{array}{l}\text { Lack of a matched control group } \\
\text { Not a randomized controlled trial }\end{array}$ \\
\hline
\end{tabular}


the results from these studies have been analysed in the PCG. In the study by Rohani et al (2019) (16), the control group received nothing and hence its results have been analysed in the PCG). The study by Salehpour et al (2010) (6) has three groups comparing the outcomes of children with CGDP receiving letrozle, oxandrolone or placebo. Hence the results of comparison between children receiving letrozole vs oxandrolone in this study has been presented as Salehpour et al 2010a (6) under the ACG. The results of comparison between children receiving letrozole vs placebo in this study has been presented as Salehpour et al 2020b (6) under the PCG.

The details of the studies included in this meta-analysis have been elaborated in Table 1. The studies which were evaluated but were excluded have been summarized in Table 2 .

\section{Risk of Bias in the Included Studies}

The summaries of risk of bias of the seven studies included in the meta-analysis have been elaborated in Figure $2 \mathrm{a}$, Figure $2 \mathrm{~b}$ and Supplementary Table 1. Random sequence generation, reporting bias and other bias were judged to be at low risk of bias in all seven studies (100\%). Source of funding, especially pharmaceutical, authors from the pharmaceutical organizations and conflict of interests were looked into in the "other bias" section. Allocation concealment bias (selection bias) were judged to be low risk in two studies $(28.57 \%$ ). Performance bias (blinding of participants and investigators) and detection bias (blinding of outcome assessors) were judged to be at low risk of bias in four out of seven studies $(57.14 \%)$. Attrition bias was judged to be at low risk in six out of seven studies $(85.71 \%)$.

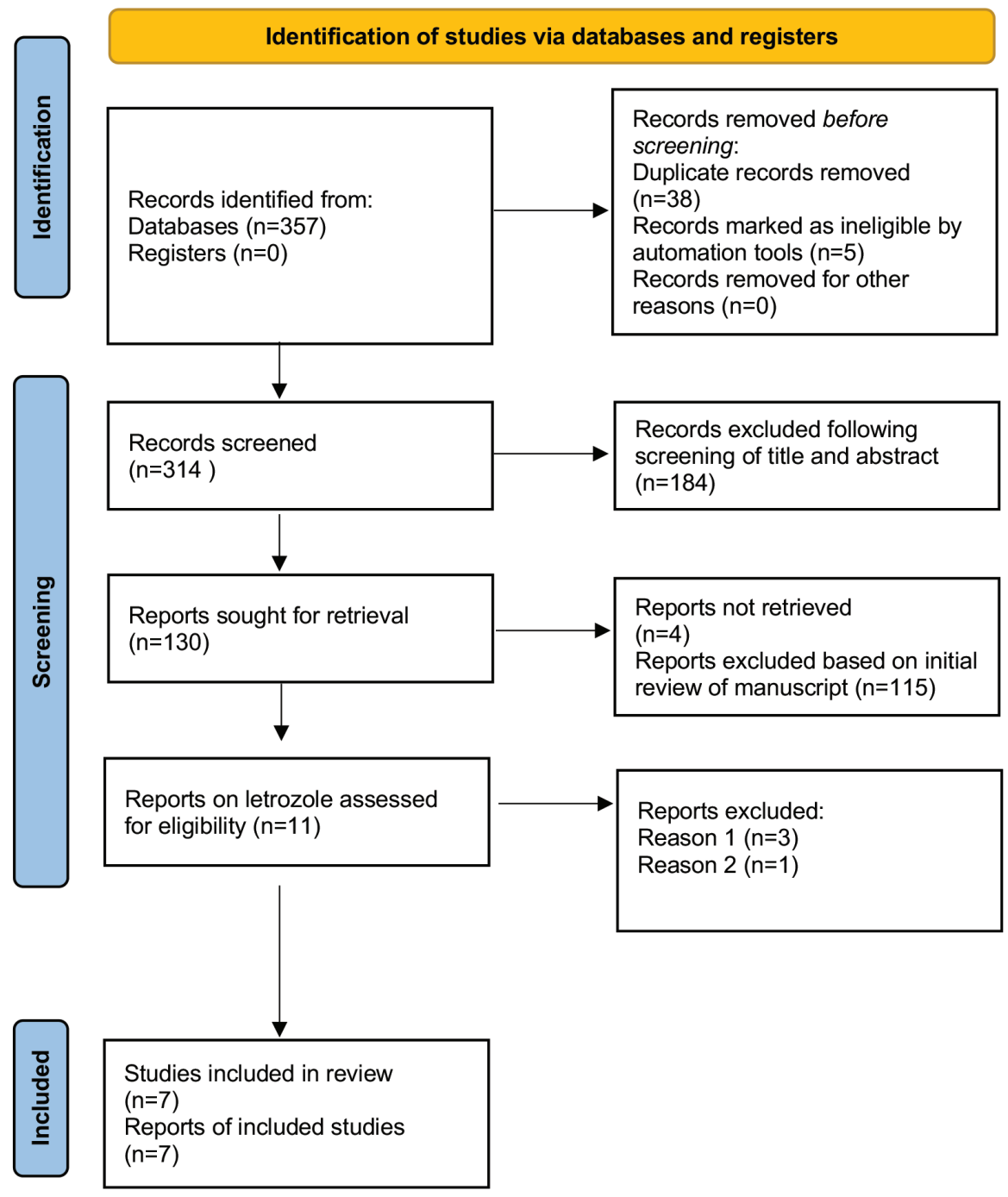

Figure 1. Flowchart elaborating on study retrieval and inclusion in the meta-analysis

$R C T$ : randomized controlled trial 


\section{Effect of Letrozole on Primary Outcomes Predicted Adult Height}

Data from two studies involving 88 children with CDGP was analysed to find out the impact of letrozole on PAH after at least 12 months of treatment, when compared to those receiving testosterone in the control group (ACG). Individuals receiving letrozole had a greater improvement in PAH but was statistically not significant when compared to those in the ACG [MD: $2.21 \mathrm{~cm}$ (95\% CI: -1.71-6.16); $\mathrm{p}=0.27 ; \mathrm{I}^{2}=98 \% \quad$ (considerable heterogeneity); Figure 3a; moderate certainty of evidence (MCE); Table 3]. Data from three studies involving 84 children with CDGP was analysed to find out the impact of letrozole on PAH after at least 12 months of treatment, when compared to those receiving placebo (PCG). Individuals receiving letrozole had a significantly greater improvement in PAH when compared to PCG [MD: $4.63 \mathrm{~cm}$ (95\% CI: 3.90-5.36); $\mathrm{p}<0.01 ; \mathrm{I}^{2}=0 \%$ (low heterogeneity); Figure 3b; high certainty of evidence (HCE); Table 3].

\section{Testicular Volume}

Data from two studies involving 57 children with CDGP was analysed to find out the impact of letrozole on testicular volume after 6 and 12 months of treatment, when compared to those receiving testosterone in the control group (ACG). After 6 months of treatment, children receiving letrozole had a significantly greater increase in testicular volume when compared to those in the ACG [MD $5.51 \mathrm{~mL}(95 \%$ CI: 2.83-8.18); $\mathrm{p}<0.01 ; \mathrm{I}^{2}=0 \%$ (low heterogeneity); Figure 3c; HCE; Table 3], which persisted even after 12 months of treatment [MD: $3.36 \mathrm{~mL}(95 \% \mathrm{CI}: 0.58-6.75) ; p=0.02$; $\mathrm{I}^{2}=0 \%$ (low heterogeneity); Figure 3d; HCE; Table 3].

Data from only one study [Wickman et al (2001) (17)] involving 19 children with CDGP was analysed to find out the impact of letrozole on testicular volume after 12 and 18 months of treatment, when compared to those receiving placebo (PCG). Children receiving letrozole had significantly higher testicular volume after 12 months [MD: $4.80 \mathrm{~mL}$ (95\% CI: 0.57-9.03); $\mathrm{p}=0.03$ ] but not after 18 months of therapy [MD: $1.90 \mathrm{~mL}$ (95\% CI: $-2.61-6.41) ; \mathrm{p}=0.41$ ], when compared to those receiving placebo.

\section{Effect of Letrozole on Secondary Outcomes \\ Height Standard Deviation Score}

Data from one study [Salehpour et al (6)] involving 61 children was available comparing the changes in Ht-SDS after at least 12 months of therapy in ACG. Data from two studies [Salehpour et al (6) and Rohani et al (16)] involving 65 children were available comparing the changes in HtSDS after at least 12 months of therapy in PCG. Children receiving letrozole had a significantly greater improvement in Ht-SDS when compared to those receiving placebo in

(2A)
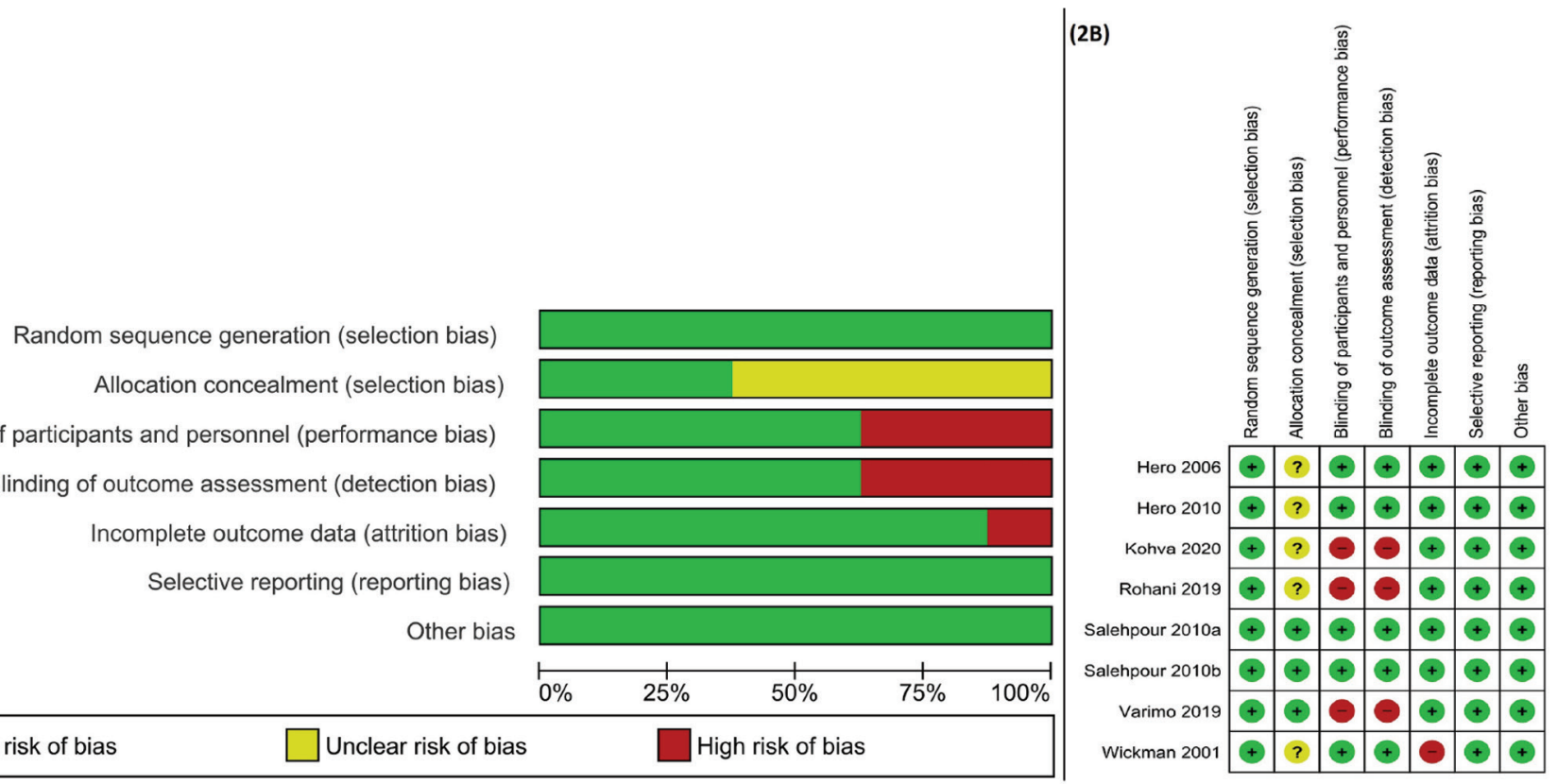

Figure 2. a) Risk of bias graph: review authors' judgements about each risk of bias item presented as percentages across all included studies. b) Risk of bias summary: review authors' judgements about each risk of bias item for each included study 
PCG [MD: + 0.63 (95\% CI: 0.52-0.74); $\mathrm{p}<0.01 ; \mathrm{I}^{2}=0 \%$ (low heterogeneity)], but not when compared to those receiving testosterone (ACG) [MD: 0.00 (95\% CI: -0.16-0.16); $\mathrm{p}=1.00$ ].

\section{Bone Age}

Data from two studies involving 88 children was analysed comparing the changes in BA after 12 months of therapy with letrozole, as compared to those receiving testosterone in the ACG. When compared to ACG, children receiving letrozole has a slower progression in $\mathrm{BA}$, which approached statistical significance [MD: -0.84 years $(95 \% \mathrm{CI}: 2.83-$ 8.18); $p=0.06 ; I^{2}=0 \%$ (low heterogeneity); Figure 3e; low certainty of evidence; Table 3].

Data from three studies involving 88 children was analysed comparing the changes in BA after 12 months of therapy with letrozole, as compared to those receiving placebo
(PCG). When compared to PCG, children receiving letrozole has similar progression in BA [MD: 0.06 years $(95 \% \mathrm{CI}$ : -0.88-0.99); $p=0.91 ; I^{2}=90 \%$ (considerable heterogeneity); Figure $3 \mathrm{f}]$.

\section{Luteinizing Hormone}

Data from two studies involving 55 children with CDGP was analysed to find out the impact of letrozole on serum LH after 6 and 12 months of treatment, when compared to those receiving testosterone in the control group (ACG). Serum LH was significantly higher after 6 months [MD: $5.28 \mathrm{IU} / \mathrm{L} \quad(95 \% \quad \mathrm{CI}: 3.16-7.40) ; \mathrm{p}<0.01 ; \mathrm{I}^{2}=0 \%$ (low heterogeneity); Figure 4a], but not after 12 months [MD: $0.05 \mathrm{IU} / \mathrm{L}\left(95 \%\right.$ CI: -0.69-0.79); $p=0.90 ; \mathrm{I}^{2}=0 \%$ (low heterogeneity); Figure 4b] of treatment with letrozole, when compared to ACG.

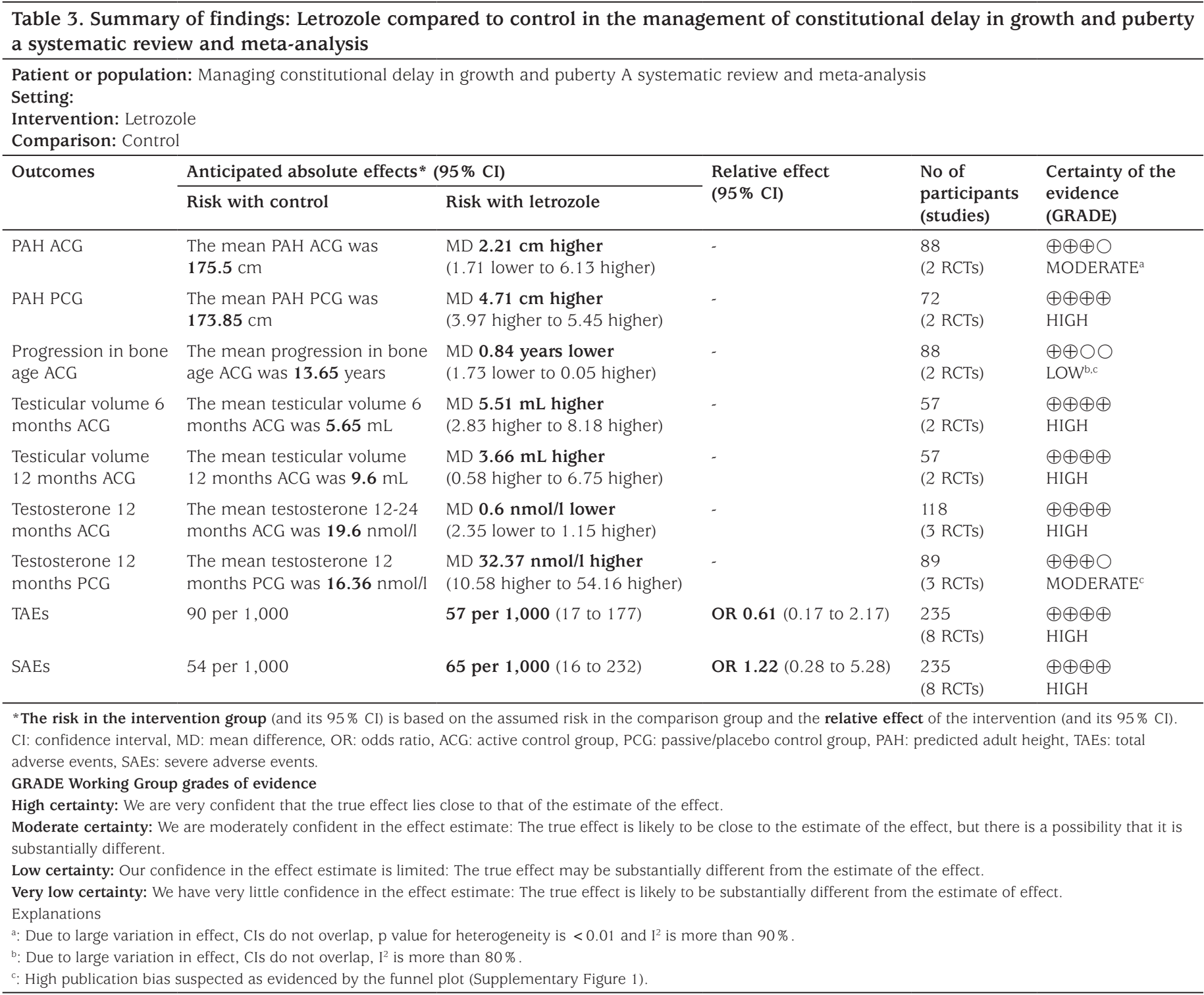


(3A)

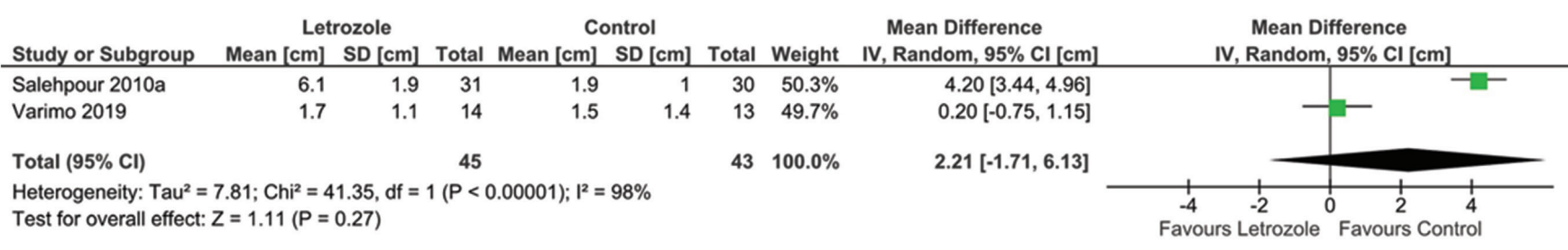

(3B)

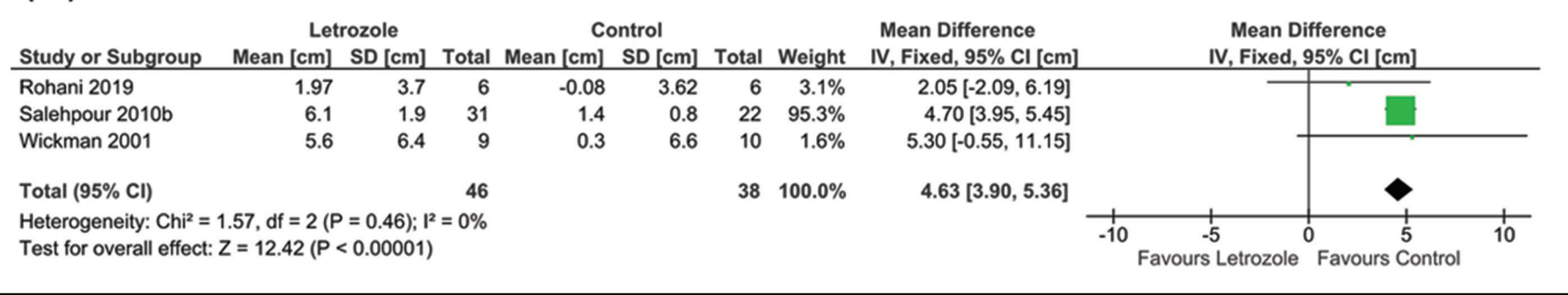

(3C)

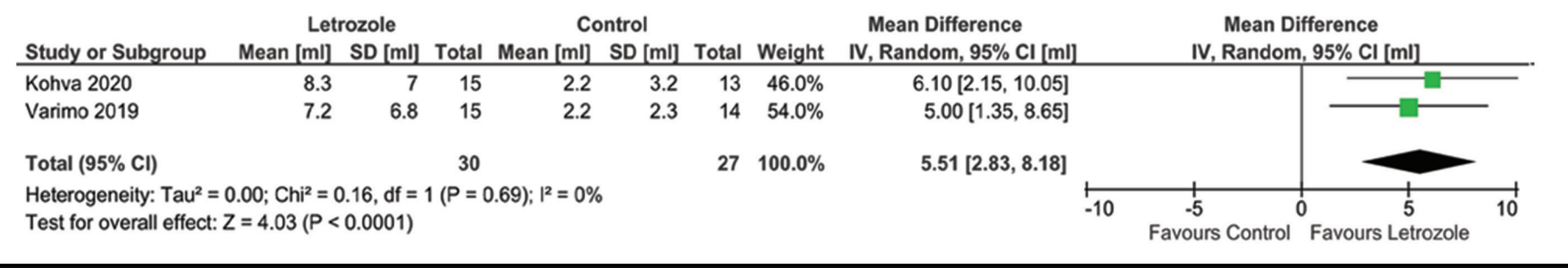

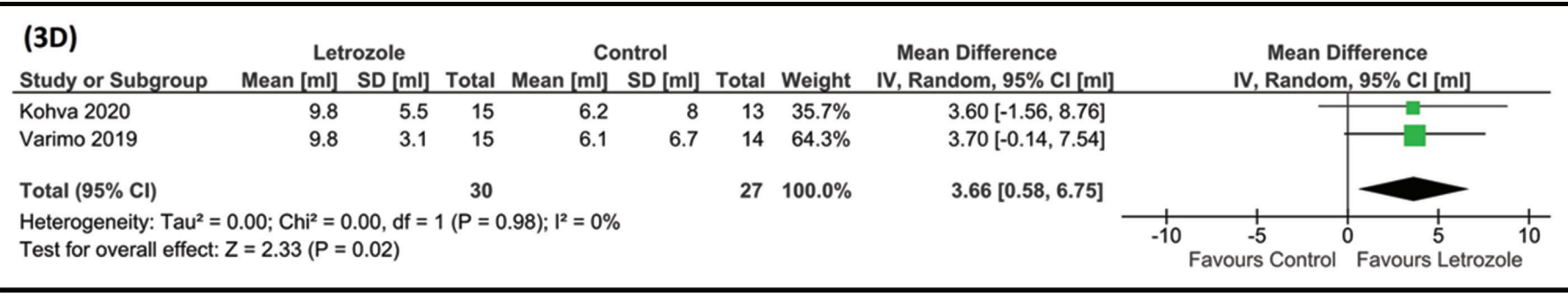

\begin{tabular}{|c|c|c|c|c|c|c|c|c|c|}
\hline $\begin{array}{l}\text { (3E) } \\
\text { Study or Subgroup }\end{array}$ & \multicolumn{3}{|c|}{ Letrozole } & \multicolumn{3}{|c|}{ Control } & \multicolumn{2}{|r|}{ Mean Difference } & $\begin{array}{c}\text { Mean Difference } \\
\text { IV, Random, } 95 \% \mathrm{Cl} \text { [years] }\end{array}$ \\
\hline Salehpour 2010a & 1.1 & 0.33 & 31 & 2.32 & 0.53 & 30 & $58.5 \%$ & $-1.22[-1.44,-1.00]$ & \begin{tabular}{l|l}
- &
\end{tabular} \\
\hline Total $(95 \% \mathrm{Cl})$ & & & 45 & & & 43 & $100.0 \%$ & $-0.84[-1.73,0.05]$ & \\
\hline $\begin{array}{l}\text { Heterogeneity: Tau } \\
\text { Test for overall effect }\end{array}$ & $\begin{array}{l}0.34 ; \mathrm{Chi}^{2}=5.00 \\
Z=1.85(P=0.0\end{array}$ & , $d f=1(P=$ & $0.03) ;$ & $\left.\right|^{2}=80 \%$ & & & & & \begin{tabular}{ccccc}
-1 & -0.5 & 0 & 0.5 & 1 \\
& \multicolumn{1}{c}{$\begin{array}{cc}1 \\
\text { Favours Letrozole }\end{array}$} & Favours Control
\end{tabular} \\
\hline
\end{tabular}

\section{(3F)} $\begin{array}{llllll}\text { Study or Subgroup Mean [years] SD [years] Total Mean [years] SD [years] Total Weight IV, Fixed, } 95 \% \text { CI [years] } & \text { I }\end{array}$

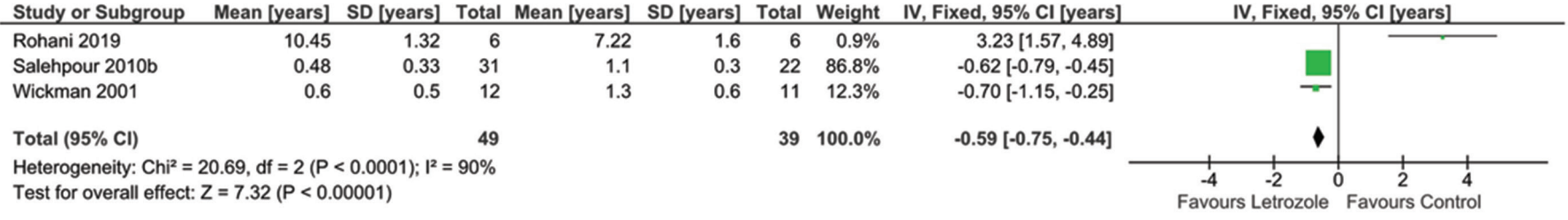

Figure 3. Forest plot highlighting the impact of letrozole on (a) Predicted adult height (PAH) in the ACG; (b) PAH in the PCG; (c) Testicular volume at 6 months in the ACG; (d) Testicular volume at 12 months in the ACG; (e): Bone age progression in ACG; (f): Bone age progression in PCG

ACG: active control group, PCG: passive/placebo control group 
(4A)

\begin{tabular}{|c|c|c|c|c|c|c|c|c|c|}
\hline \multirow[b]{2}{*}{ Study or Subgroup } & \multicolumn{3}{|c|}{ Letrozole } & \multicolumn{3}{|c|}{ Control } & \multicolumn{2}{|r|}{ Mean Difference } & \multirow{2}{*}{$\begin{array}{l}\text { Mean Difference } \\
\text { IV, Fixed, } 95 \% \mathrm{Cl}[\mathrm{IU} / \mathrm{L}]\end{array}$} \\
\hline & Mean [IU/L] & $S D$ [IU/L] & Total & Mean [IU/L] & SD [IU/L] & Total & Weight & IV, Fixed, 95\% CI [IU/L] & \\
\hline Kohva 2020 & 5.5 & 6.7 & 15 & -0.1 & 1.8 & 13 & $36.0 \%$ & $5.60[2.07,9.13]$ & \\
\hline Varimo 2019 & 5 & 4.7 & 14 & -0.1 & 1.8 & 13 & $64.0 \%$ & $5.10[2.45,7.75]$ & \\
\hline Total $(95 \%$ Cl) & & & 29 & & & 26 & $100.0 \%$ & $5.28[3.16,7.40]$ & \\
\hline \multicolumn{4}{|c|}{$\begin{array}{l}\text { Heterogeneity: } \mathrm{Chi}^{2}=0.05, \mathrm{df}=1(P=0.82) ; 1^{2}=0 \% \\
\text { Test for overall effect: } Z=4.88(P<0.00001)\end{array}$} & & & & & & $\begin{array}{ccccc}-4 & -2 & 0 & 2 & 4 \\
\text { Favours Letrozole } & \text { Favours Contr }\end{array}$ \\
\hline
\end{tabular}

\section{(4B)}

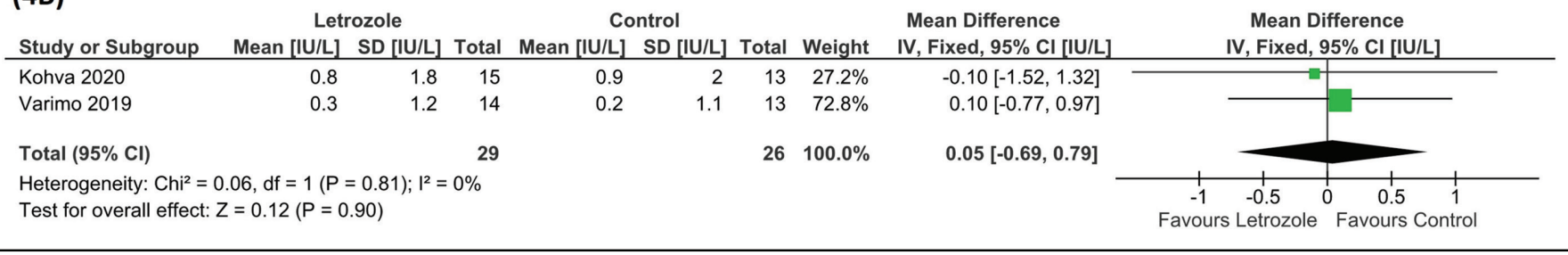

\section{(4C)}

Study or Subgroup Mean [IU/L] SD [IU/L] Total Mean [IU/L] SD [IU/L

\begin{tabular}{|c|c|c|c|c|c|c|c|c|}
\hline Kohva 2020 & 4.5 & 6.1 & 15 & 0.4 & 2.2 & 13 & $43.1 \%$ & $4.10[0.79,7.41]$ \\
\hline Varimo 2019 & 3.4 & 4.6 & 14 & 0.2 & 2.9 & 13 & $56.9 \%$ & $3.20[0.32,6.08]$ \\
\hline
\end{tabular}

Heterogeneity: $\mathrm{Chi}^{2}=0.16, \mathrm{df}=1(\mathrm{P}=0.69) ; \mathrm{I}^{2}=0 \%$

Test for overall effect: $Z=3.24(P=0.001)$

$26 \quad 100.0 \%$

$3.59[1.42,5.76]$

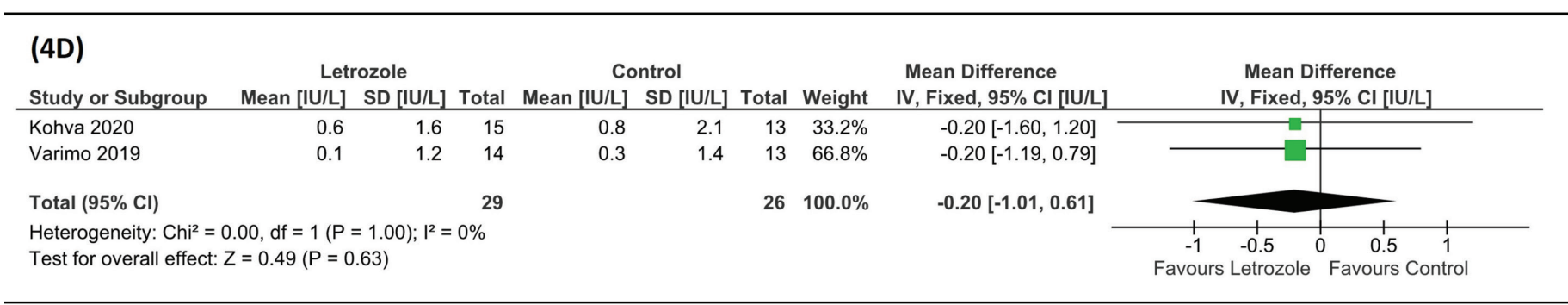

\section{(4E)}

Letrozole Control Mean Difference

I/L] SD [mmol/L] Total Weight IV, Random, $95 \% \mathrm{CI}[\mathrm{mmol} / \mathrm{L}]$

\begin{tabular}{lrrrrrrrr} 
Study or Subgroup & Mean [mmol/L] & SD [mmol/L] & Total & Mean [mmol/L] & SD [mmol/L] & Total & Weight & IV, Random, $95 \%$ Cl[mmol/L] \\
\hline Kohva 2020 & 28.3 & 25.1 & 15 & 3.5 & 5.7 & 13 & $35.3 \%$ & $24.80[11.73,37.87]$ \\
Varimo 2019 & 28 & 18.6 & 15 & 6.4 & 4.1 & 14 & $64.7 \%$ & $21.60[11.95,31.25]$
\end{tabular}

30

Heterogeneity: $\mathrm{Tau}^{2}=0.00 ; \mathrm{Chi}^{2}=0.15, \mathrm{df}=1(\mathrm{P}=0.70) ; \mathrm{I}^{2}=0 \%$

Test for overall effect: $Z=5.74(P<0.00001)$
$27100.0 \%$
$22.73[14.96,30.50]$

\section{(4F)}

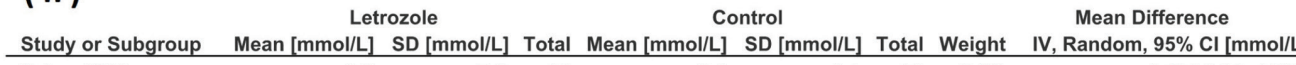

$\begin{array}{lrrrrrrr}\text { Kohva 2020 } & 8.2 & 7.5 & 15 & 9.3 & 8.1 & 13 & 9.1 \% \\ \text { Salehpour 2010a } & 15.66 & 4.88 & 31 & 17.13 & 5.11 & 30 & 48.6 \% \\ \text { Varimo 2019 } & 8.1 & 3.2 & 15 & 7.6 & 4.1 & 14 & 42.3 \%\end{array}$

Varimo 2019

Total $(95 \% \mathrm{Cl})$
Heterogeneity: $\mathrm{Tau}^{2}=0.00 ; \mathrm{Chi}^{2}=1.13, \mathrm{df}=2(\mathrm{P}=0.57) ; \mathrm{I}^{2}=0 \%$

Heterogeneity: $\mathrm{Tau}^{2}=0.00 ; \mathrm{Chi}^{2}=1.13$, d $=$
Test for overall effect: $Z=0.68(P=0.50)$

$57100.0 \%$

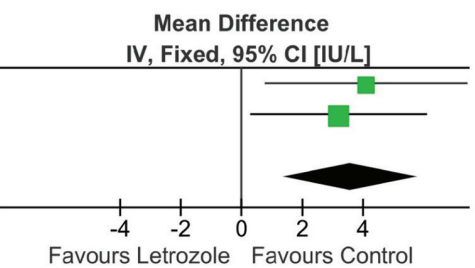

Figure 4. Forest plot highlighting the impact of letrozole vs the active control group on (a) Luteinizing hormone at 6 months; (b) Luteinizing hormone at 12 months; (c) Follicle stimulating hormone at 6 months; (d) Follicle stimulating hormone at 12 months; (e): Testosterone at 6 months; (f): Testosterone at 12 months 
Data from one study [Hero et al 2006 (13)] involving 17 children with CDGP was analysed to find out the impact of letrozole on serum LH after 6 and 12 months of treatment, when compared to those receiving placebo (PCG). Serum LH was significantly higher after 6 months [MD: 6.50 IU/L (95\% CI: 3.40-9.60); $p<0.01$ ], and 12 months [MD: 5.10 IU/L (95\% CI: 2.14-8.06); $p<0.01]$ of treatment with letrozole.

\section{Follicle Stimulating Hormone}

Data from two studies involving 55 children with CDGP was analysed to find out the impact of letrozole on serum FSH after 6 and 12 months of treatment, when compared to those receiving testosterone in the control group (ACG). Serum FSH was significantly higher after 6 months [MD: 3.59 IU/L (95\% CI: 1.42-5.76); $\mathrm{p}<0.01 ; \mathrm{I}^{2}=0 \%$ (low heterogeneity); Figure 4C], but not after 12 months [MD: $-0.20 \mathrm{IU} / \mathrm{L}$ (95\% CI: $-1.21-0.61$ ); $p=0.63 ; \mathrm{I}^{2}=0 \%$ (low heterogeneity); Figure $4 \mathrm{~d}]$ of treatment with letrozole, when compared to ACG.

Data from one study [Hero et al 2006 (13)] involving 17 children with CDGP was analysed to find out the impact of letrozole on serum FSH after 6 and 12 months of treatment, when compared to those receiving placebo (PCG). Serum FSH was significantly higher after 6 months [MD: 7.70 IU/L (95\% CI: 4.37-11.03); $p<0.01$ ], and 12 months [MD: $2.70 \mathrm{IU} / \mathrm{L}(95 \% \mathrm{CI}: 0.42-4.98) ; p=0.02]$ of treatment with letrozole.

\section{Testosterone}

Data from two studies involving 57 children with CDGP was analysed to find out the impact of letrozole on serum total testosterone after 6 months of treatment, when compared to those receiving testosterone in the control group (ACG). Serum total testosterone was significantly higher after 6 months [MD: $22.73 \mathrm{mmol} / \mathrm{L}$ (95\% CI: 14.96-30.50); $p<0.01 ; I^{2}=0 \%$ (low heterogeneity); Figure 4e], treatment with letrozole, when compared to ACG. Data from three studies involving 118 children with CDGP was analysed to find out the impact of letrozole on serum total testosterone after 12 months of treatment, when compared to those receiving testosterone in the control group (ACG). Serum total testosterone was not significantly different after 12-24 months [MD: $-0.60 \mathrm{mmol} / \mathrm{L}$ (95\% CI: -2.35-1.15); $\mathrm{p}=0.50$; $\mathrm{I}^{2}=0 \%$ (low heterogeneity); Figure 4f; HCE; Table 3], treatment with letrozole, when compared to ACG.

Data from one study [Hero et al 2006 (13)] involving 17 children with CDGP was analysed to find out the impact of letrozole on serum total testosterone after 6 months of treatment, when compared to those receiving placebo (PCG). Serum testosterone was significantly higher after 6 months [MD: $49.20 \mathrm{mmol} / \mathrm{L}$ (95\% CI: 22.05-76.35); $p<0.01]$, of treatment with letrozole. Data from three studies [Hero et al 2006 (13), Salehpour et al (6) and Wickman et al (2001) (17)] involving 89 children with CDGP was analysed to find out the impact of letrozole on serum total testosterone after 12 months of treatment, when compared to those receiving placebo (PCG). Serum total testosterone was significantly higher after 12 months [MD: $32.37 \mathrm{mmol} / \mathrm{L}$ (95\% CI: 10.5854.16); $\mathrm{p}<0.01 ; \mathrm{I}^{2}=97 \%$ (considerable heterogeneity); MCE; Table 2] treatment with letrozole, when compared to PCG.

\section{Inhibin-B}

Data from two studies involving 57 children with CDGP was analysed to find out the impact of letrozole on serum inhibin-B after 6 and 12 months of treatment, when compared to those receiving testosterone in the control group (ACG). Serum inhibin-B was significantly higher after 6 months [MD: 62.97 ng/L (95\% CI: 24.50-101.43); $\mathrm{p}<0.01 ; \mathrm{I}^{2}=0 \%$ (low heterogeneity); Figure 5a], and 12 months [MD: 25.40 ng/L (95\% CI: 1.51-49.29); $p=0.04$; $\mathrm{I}^{2}=0 \%$ (low heterogeneity); Figure $\left.5 \mathrm{~b}\right]$ of treatment with letrozole, when compared to ACG.

Data from one study [Wickman et al (2001) (17)] involving 19 children with CDGP was analysed to find out the impact of letrozole on serum inhibin-B after 5, 12 and 18 months of treatment, when compared to those receiving placebo (PCG). Serum inhibin-B was significantly higher only after 5 months [MD: $64.00 \mathrm{ng} / \mathrm{L}$ (95\% CI: 27.84-100.16); p<0.01], but not 12 month [MD: 35.00 ng/L (95\% CI: -6.01 76.01); $\mathrm{p}=0.09$ ], and 18 months [MD: $-5.00 \mathrm{ng} / \mathrm{L}(95 \% \mathrm{CI}$ : -43.46-33.46); $p=0.80]$ of treatment with letrozole, when compared to PCG.

\section{Insulin Like Growth Factor-1}

Data from two studies [Kohva et al (2020) (15) and Varimo et al (2019) (5)] involving 57 children with CDGP was analysed to find out the impact of letrozole on serum IGF-1 after 6 months of treatment, when compared to those receiving testosterone in the control group (ACG). Serum IGF-1 was significantly lower after 6 months [MD: $-11.86 \mathrm{nmol} / \mathrm{L}$ (95\% CI: -18.08- -5.64); $\mathrm{p}<0.01 ; \mathrm{I}^{2}=0 \%$ (low heterogeneity)], of treatment with letrozole, when compared to ACG. Data from three studies [Kohva et al (2020) (15) Salehpour et al (6) and Varimo et al (2019) (5)] involving 118 children with CDGP was analysed to find out the impact of letrozole on serum IGF-1 after 12-24 months of treatment, when compared 
to those receiving testosterone in the control group (ACG). Serum IGF-1 was not significantly different after 12-24 months [MD: $-1.24 \mathrm{nmol} / \mathrm{L}$ (95\% CI: -8.70-6.22); $\mathrm{p}=0.74$; $\mathrm{I}^{2}=0 \%$ (low heterogeneity)] of treatment with letrozole, when compared to ACG.

Data from one study [Wickman et al (2001) (17)] involving 19 children with CDGP was analysed to find out the impact of letrozole on serum IGF-1 after 6 and 12 months of treatment, when compared to those receiving placebo (PCG). Serum IGF-1 was significantly lower after 6 months [MD: $-11.30 \mathrm{nmol} / \mathrm{L}(95 \% \mathrm{CI}:-19.39--3.21) ; \mathrm{p}<0.01$ ], and 12 months [MD: $-9.00 \mathrm{nmol} / \mathrm{L}$ (95\% CI: -14.52 - -3.48); $p<0.01]$ of treatment with letrozole, when compared to PCG.

\section{Safety}

Data from seven studies (235 children) was analysed to evaluate the impact of letrozole on the occurrence of adverse events [(total adverse events (TAEs) and severe adverse events (SAEs)], over 1-4 years of treatment. The occurrence of TAEs [RR 0.61 (95\% CI: 0.17-2.17); $p=0.45$; $\mathrm{I}^{2}=0 \%$ (low heterogeneity); Figure 6a; HCE; Table 3] and SAEs [RR 1.22 (95\% CI: 0.28-5.28); $p=0.79 ; I^{2}=0 \%$ (low heterogeneity); Figure 6b; HCE; Table 3] was not statistically different in children receiving letrozole as compared to the control group.

Vertebral deformity and end-plate deformity was investigated in the study by Hero et al 2010 (14). In that study data from 12 children 6 receiving letrozole with testosterone vs 6 receiving placebo with testosterone) was analysed after 4.2 years follow up. The occurrence of vertebral deformity [RR 0.28 (95\% CI: 0.01-8.42); $p=0.47]$ and end-plate deformity
[RR 0.50 (95\% CI: 0.05-5.15); $p=0.56$ ] was not statistically different in children receiving letrozole as compared to the control group.

Changes in the BMD Z-scores, before and after therapy was noted in the study by Salehpour et al (6). A significantly lower (improvement) in lumbar spine BMD Z-score [MD: -2.59 (95\% CI: $-2.88-2.30) ; \mathrm{p}<0.01 ; \mathrm{n}=61$ ] and femoral neck BMD Z-score [MD: -2.2 (95\% CI: -2.55 - -1.85); $\mathrm{p}<0.01 ; n=61$ ] was noted in children receiving letrozole as compared to those receiving testosterone in the control group (ACG). Changes in lumbar spine BMD Z-score [MD: 0.11 (95\% Cl: $-0.35-0.57) ; p=0.64 ; n=61]$ and femoral neck BMD Z-score [MD: 0.10 (95\% CI: -0.25-0.45); $p=0.58$; $\mathrm{n}=61]$ was not significantly different when comparing children receiving letrozole to those receiving placebo (PCG).

A small decline in high density lipoprotein-cholesterol (HDL-C) was noted in children receiving letrozole as compared to those receiving placebo in a cohort of 69 patients from two studies [MD: $-0.77 \mathrm{mmol} / \mathrm{L}(95 \% \mathrm{CI}$ : -2.00-0.47); $\mathrm{p}=0.22 ; \mathrm{I}^{2}=99 \%$ (considerable heterogeneity); Figure 6c], which was however statistically not significant.

\section{Discussion}

This is the first meta-analysis to highlight the efficacy and safety of letrozole in children with CDGP. An important observation from this meta-analysis is letrozole use in children with CDGP is associated with a significantly greater improvement in PAH when compared to receiving placebo. This improvement in PAH with letrozole is comparable to the improvements seen with the use of testosterone in CDGP. In accordance with the previous observation, children receiving letrozole had a significantly greater improvement

\begin{tabular}{|c|c|c|c|c|c|c|c|c|c|c|}
\hline Study or Subgroup & \multicolumn{2}{|c|}{ Letrozole } & \multicolumn{4}{|c|}{ Control } & \multicolumn{2}{|r|}{ Mean Difference } & \multirow{2}{*}{\multicolumn{2}{|c|}{$\begin{array}{c}\text { Mean Difference } \\
\text { IV, Random, } 95 \% \mathrm{CI}[\mathrm{ng} / \mathrm{L}]\end{array}$}} \\
\hline Kohva 2020 & 37 & 88 & 15 & -34 & 71 & 13 & $42.6 \%$ & $71.00[12.07,129.93]$ & & \\
\hline Varimo 2019 & 21 & 68.1 & 15 & -36 & 71.2 & 14 & $57.4 \%$ & $57.00[6.22,107.78]$ & & \\
\hline Total $(95 \% \mathrm{Cl})$ & & & 30 & & & 27 & $100.0 \%$ & $62.97[24.50,101.43]$ & & \\
\hline $\begin{array}{l}\text { Heterogeneity: Tau } \\
\text { Test for overall effect }\end{array}$ & $\begin{array}{l}.00 ; \mathrm{Chi}^{2}=0.1 \\
=3.21(\mathrm{P}=0 .\end{array}$ & $\begin{array}{l}\text { 2, df }=1(P= \\
D 01)\end{array}$ & $=0.72)$ & $; 1^{2}=0 \%$ & & & & & $\begin{array}{ll}-100 & -50 \\
\text { Favours Letrozole }\end{array}$ & $\begin{array}{lcc}0 & 50 & 100 \\
\text { Favours Control }\end{array}$ \\
\hline
\end{tabular}

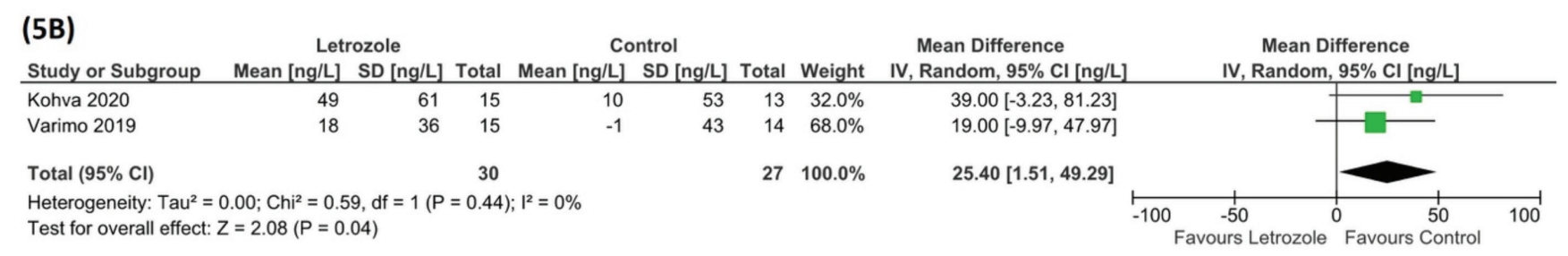

Figure 5. Forest plot highlighting the impact of letrozole vs the active control group on (a) Inhibin-B at 6 months; (b) Inhibin-B at 12 months 
(6A)

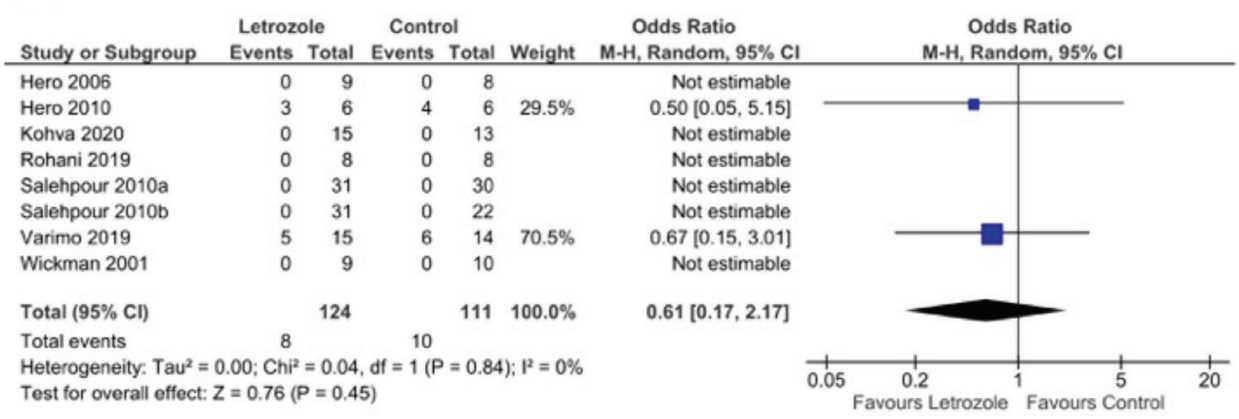

(6B)

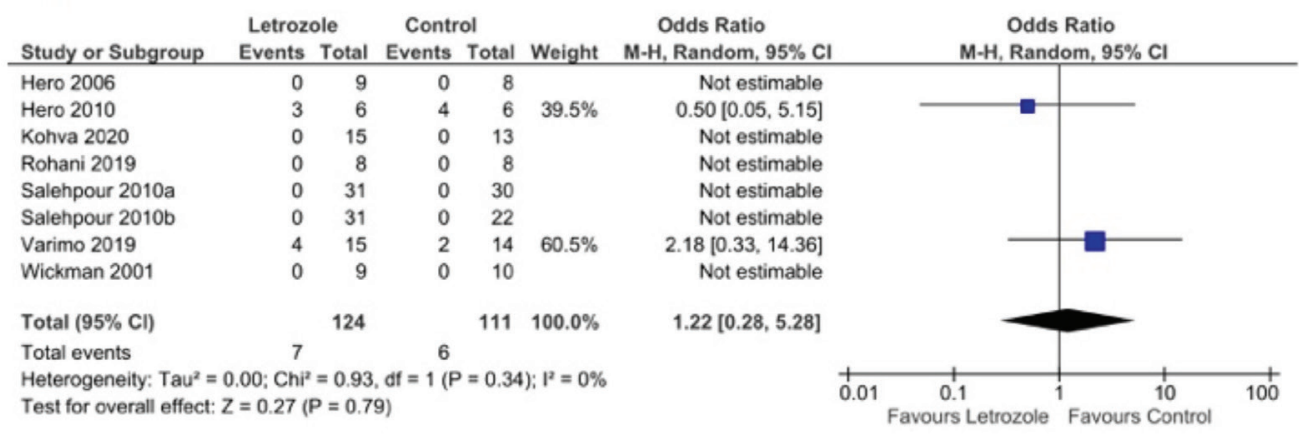

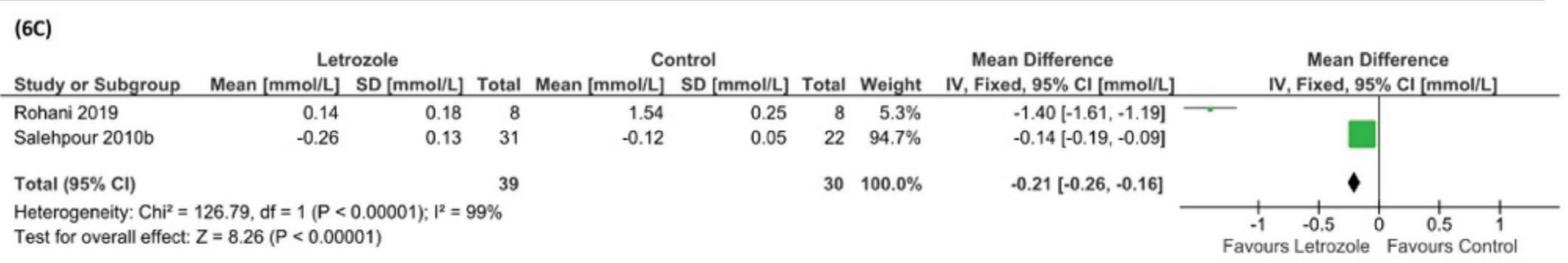

Figure 6. Forest plot highlighting the side effect profile of the use of letrozole as compared to controls focussing on (a): Total adverse events (TAEs); (b): Severe adverse events (SAEs); (c): High density lipoprotein cholesterol

in Ht-SDS when compared to those receiving placebo but not testosterone. Six months and 12 months letrozole use was associated with a significantly greater improvement in testicular volume in CDGP when compared to both placebo and testosterone. All studies used letrozole in dose of 2.5 $\mathrm{mg} /$ day for the duration of the study.

Use of letrozole in CDGP was associated with a slower progression in BA when compared to those receiving placebo or testosterone. Serum LH, FSH, total testosterone and inhibin-B were significantly higher after 6 months of use of letrozole in children with CDGP, when compared to those receiving placebo or testosterone. After 12 months of use, the difference for LH, FSH and testosterone persisted only when compared to placebo, but not with regards to those receiving testosterone. Inhibin-B continued to be significantly higher in children receiving letrozole as compared to testosterone after 12 months of use.
Serum IGF-1 was significantly lower after 6 months use of letrozole when compared to those receiving placebo or testosterone. Oestrogen has a trophic impact on growth hormone through paracrine effects, which indirectly has a trophic impact on IGF-1 levels (22). Letrozole is an aromatase inhibitor associated with lower oestrogen levels. Testosterone in contrast is aromatized to oestrogen to some extent in the body, having a trophic impact on $\mathrm{GH}$ release from pituitary, explaining the higher IGF-1 levels at 6 months (22). Pubertal BA progression is associated with higher IGF-1 levels (23). A lower BA progression may contribute to the marginally lower IGF-1 levels in the first 6 months use of letrozole. It is important to note that this observation is transient and the difference did not persist after 12 months of clinical use. After 12 months use, IGF-1 levels were comparable in children receiving letrozole or testosterone. 
This meta-analysis provided reassuring data regarding the long term safety of letrozole use in CDGP. No increased occurrence of TAEs and SAEs were noted with the use of letrozole. The occurrence of vertebral deformities was not significantly increased. No significant decline/change in BMD Z-scores were noted in children receiving letrozole as compared to placebo. Bone health outcomes were better in children receiving testosterone as compared to letrozole because of the anabolic impact of testosterone on BMD. Testosterone is aromatized to estrogen in the body which has a direct impact on increased bone formation (24). A mild statistically not-significant decline in the good cholesterol HDL-C was noted in children receiving letrozole. This is an observation and its impact on long term cardiovascular outcomes needs further evaluation. Advantages of letrozole over testosterone also includes its oral administration in contrast to monthly injections with regards to testosterone.

\section{Conclusion}

To conclude, it may be said that this first meta-analysis on the efficacy and safety of letrozole in CDGP, provides us with reassuring data on the good efficacy and tolerability of this molecule on height outcomes and pubertal progression. Letrozole in comparable to testosterone and superior to placebo with regards to improving height outcomes in CDGP. Letrozole tended to show a better slowing effect on $\mathrm{BA}$ progression, when compared to both testosterone and placebo. This may have an additional impact on improving height outcomes. Letrozole is superior to both testosterone and placebo with regards to improvement in testicular volume (an important marker of pubertal progression in boys). Letrozole has a better short term impact on hormonal markers of pubertal progression (LH, FSH, testosterone and inhibin-B).

\section{Ethics}

Peer-review: Externally peer-reviewed.

\section{Authorship Contributions}

Concept: Deep Dutta, Design: Deep Dutta, Meha Sharma, Data Collection or Processing: Deep Dutta, Rajiv Singla, Vineet Surana, Meha Sharma, Analysis or Interpretation: Deep Dutta, Rajiv Singla, Vineet Surana, Meha Sharma, Literature Search: Deep Dutta, Rajiv Singla, Vineet Surana, Meha Sharma, Writing: Deep Dutta, Rajiv Singla, Vineet Surana, Meha Sharma.

Financial Disclosure: The authors declared that this study received no financial support.

\section{References}

1. Raivio T, Miettinen PJ. Constitutional delay of puberty versus congenital hypogonadotropic hypogonadism: Genetics, management and updates. Best Pract Res Clin Endocrinol Metab 2019;33:101316. Epub 2019 Sep 5

2. Gohil A, Eugster EA. Delayed and Precocious Puberty: Genetic Underpinnings and Treatments. Endocrinol Metab Clin North Am 2020;49:741-757

3. Dye AM, Nelson GB, Diaz-Thomas A. Delayed Puberty. Pediatr Ann 2018;47:16-22.

4. Wei C, Crowne EC. Recent advances in the understanding and management of delayed puberty. Arch Dis Child 2016;101:481-488. Epub 2015 Sep 9

5. Varimo T, Huopio H, Kariola L, Tenhola S, Voutilainen R, Toppari J, Toiviainen-Salo S, Hämäläinen E, Pulkkinen MA, Lääperi M, Tarkkanen A, Vaaralahti K, Miettinen PJ, Hero M, Raivio T. Letrozole versus testosterone for promotion of endogenous puberty in boys with constitutional delay of growth and puberty: a randomised controlled phase 3 trial. Lancet Child Adolesc Health 2019;3:109-120. Epub 2019 Jan 4

6. Salehpour S, Alipour P, Razzaghy-Azar M, Ardeshirpour L, Shamshiri A, Monfared MF, Gharib A. A double-blind, placebo-controlled comparison of letrozole to oxandrolone effects upon growth and puberty of children with constitutional delay of puberty and idiopathic short stature. Horm Res Paediatr 2010;74:428-435. Epub 2010 Jul 14

7. Punjani N, Bernie H, Salter C, Flores J, Benfante N, Mulhall JP. The Utilization and Impact of Aromatase Inhibitor Therapy in Men With Elevated Estradiol Levels on Testosterone Therapy. Sex Med 2021;9:100378. Epub 2021 Jun 3

8. Monteverdi S, Pedersini R, Gallo F, Maffezzoni F, Dalla Volta A, Di Mauro P, Turla A, Vassalli L, Ardine M, Formenti AM, Simoncini EL, Giustina A, Maroldi R, Amoroso V, Berruti A. The Interaction of Lean Body Mass With Fat Body Mass Is Associated With Vertebral Fracture Prevalence in Women With Early Breast Cancer Undergoing Aromatase Inhibitor Therapy. JBMR Plus 2020;5:e10440.

9. Higgins JP, Altman DG, Gøtzsche PC, Jüni P, Moher D, Oxman AD, Savovic J, Schulz KF, Weeks L, Sterne JA; Cochrane Bias Methods Group; Cochrane Statistical Methods Group. The Cochrane Collaboration's tool for assessing risk of bias in randomised trials. BMJ 2011;343:d5928.

10. Liberati A, Altman DG, Tetzlaff J, Mulrow C, Gøtzsche PC, Ioannidis JP, Clarke M, Devereaux PJ, Kleijnen J, Moher D. The PRISMA statement for reporting systematic reviews and metaanalyses of studies that evaluate healthcare interventions: explanation and elaboration. BMJ 2009;339:b2700.

11. Guyatt GH, Oxman AD, Vist GE, Kunz R, Falck-Ytter Y, AlonsoCoello P, Schünemann HJ; GRADE Working Group. GRADE: an emerging consensus on rating quality of evidence and strength of recommendations. BMJ 2008;336:924-926

12. Song F, Eastwood AJ, Gilbody S, Duley L, Sutton AJ. Publication and related biases. Health Technol Assess 2000;4:1-115.

13. Hero M, Wickman S, Dunkel L. Treatment with the aromatase inhibitor letrozole during adolescence increases near-final height in boys with constitutional delay of puberty. Clin Endocrinol (Oxf) 2006;64:510-513.

14. Hero M, Toiviainen-Salo S, Wickman S, Mäkitie O, Dunkel L. Vertebral morphology in aromatase inhibitor-treated males with idiopathic short stature or constitutional delay of puberty. J Bone Miner Res 2010;25:1536-1543.

15. Kohva E, Varimo T, Huopio H, Tenhola S, Voutilainen R, Toppari J, Miettinen PJ, Vaaralahti K, Viinamäki J, Backman JT, Hero M, Raivio T. Anti-Müllerian hormone and letrozole levels in boys with constitutional 
delay of growth and puberty treated with letrozole or testosterone Hum Reprod 2020;35:257-264.

16. Rohani F, Asadi R, Mirboluk AA, Soheilipour F. Letrozole Effect on Final Height of Patients with Constitutional Delay of Growth and Puberty. Med Arch 2019;73:307-310.

17. Wickman S, Sipilä I, Ankarberg-Lindgren C, Norjavaara E, Dunkel L. A specific aromatase inhibitor and potential increase in adult height in boys with delayed puberty: a randomised controlled trial. Lancet 2001;357:1743-1748.

18. Zhao X, Zhang $\mathrm{Q}$. [Clinical efficacy of letrozole in boys with idiopathic central precocious puberty]. Zhongguo Dang Dai Er Ke Za Zhi 2014;16:397-400.

19. Karmazin A, Moore WV, Popovic J, Jacobson JD. The effect of letrozole on bone age progression, predicted adult height, and adrenal gland function. J Pediatr Endocrinol Metab 2005;18:285-293.

20. Neely EK, Kumar RB, Payne SL, Ranadive SA, Suchet DI. Letrozole vs anastrozole for height augmentation in short pubertal males: first year data. J Clin Endocrinol Metab 2014;99:4086-4093. Epub 2014 Aug 19
21. Xu Y, Zhang YH, Zhang QP, Zhao QQ, Cao XF, Zhang M, Li X, Liu XT, Sun ZX, Kan M, Du B, Zhou Y, Yang F, Ban B, Zhao W. Off-label use of letrozole in Chinese short pubertal boys: Effectiveness, safety, and exposure-response analysis. Br J Clin Pharmacol 2021;87:3599-3607. Epub 2021 Mar 2

22. Birzniece V, Ho KKY. Mechanisms in endocrinology: Paracrine and endocrine control of the growth hormone axis by estrogen. Eur J Endocrinol 2021;184:269-278.

23. Choi YJ, Lee YJ, Lee NY, Lee SH, Kim SK, Ahn MB, Kim SH, Cho WK, Cho KS, Jung MH, Suh BK. Discriminatory performance of insulin-like growth factor 1 and insulin-like growth factor binding protein-3 by correlating values to chronological age, bone age, and pubertal status for diagnosis of isolated growth hormone deficiency. Ann Pediatr Endocrinol Metab 2020;25:240-247. Epub 2020 Jul 30

24. Kumar M, Mukhopadhyay S, Dutta D. Challenges and controversies in diagnosis and management of gonadotropin dependent precocious puberty: An Indian perspective. Indian J Endocrinol Metab 2015;19:228235.

\section{Click for Supplementary Figure 1, Supplementary Table 1 access link: http://glns.co/qvqp6}

